\title{
CONSTRUÇÃO E VALIDAÇÃO DO QUESTIONÁRIO DE CONHECIMENTOS DA DOENÇA PARA PACIENTES COM CÂNCER
}

\author{
CONSTRUCTION AND VALIDATION OF KNOWLEDGE QUESTIONNAIRE \\ FOR CANCER PATIENTS
}

Moacir Pereira Junior

Magnus Benetti

Orientador

\section{Programa de Pós-Graduação em Ciências do Movimento Humano Universidade Estadual de Santa Catarina}

Introdução: Os instrumentos de avaliação são utilizados em programas educativos na área da saúde, pois possibilitam mensurar os efeitos do processo de ensino-aprendizagem, constituindose uma forma de conhecer as necessidades dos indivíduos e as condições para a implementação de um processo educativo. Existem evidências de que muitos pacientes não têm conhecimento prévio sobre o câncer, porém, eles relatam que têm preocupação em cuidar do seu estado de saúde geral. Dessa forma, necessita-se construir um instrumento direcionado a pacientes com câncer, para a avaliação do conhecimento sobre sua própria doença. Objetivos: Construir e validar o instrumento "Questionário de conhecimentos da doença para pacientes com câncer - CÂNCER-Q" Método: O instrumento foi construído com base em uma revisão da literatura específica da área do câncer para apresentação dos itens a uma equipe multidisciplinar da área da saúde, sendo cinco médicos, quatro fisioterapeutas, quatro educadores físicos, dois psicólogos, um farmacêutico e um nutricionista, totalizando 17 profissionais, que fizeram a validade de conteúdo do instrumento. Em seguida, gerou-se a versão piloto; e após as análises, o instrumento foi aplicado para avaliar o nível de conhecimento sobre a doença em 71 pacientes com câncer do Centro de Pesquisas Oncológicas (CEPON), sendo 47 mulheres e 24 homens, todos com diagnóstico clínico de câncer com tempo médio de diagnóstico de 29 meses, com média de idade de 51 anos. A reprodutibilidade foi obtida por meio do coeficiente de correlação intraclasse do método de teste e reteste para analisar a confiabilidade e a estabilidade do instrumento, tomando por base o valor maior que 0,8 ; a consistência interna foi verificada pela alfa de Cronbach. Resultados: A versão final do instrumento obteve 14 questões e apresentou um índice de clareza de $8,63 \pm 0,75$ obtido pela média das notas dos especialistas sobre cada questão. O valor do Coeficiente de Correlação Intraclasse foi de 0,858 ; e do alfa de Cronbach, 0,611. Quanto à aplicação do questionário de conhecimento, o instrumento revelou um escore total de $35,66 \pm 4,9$, com mediana de 37. Foi observada a prevalência da classificação do tipo "bom conhecimento". Os escores finais foram comparados com as características dos pacientes, em que se concluiu que baixa escolaridade e a baixa renda estão associadas a baixos escores de conhecimento. A análise fatorial exploratória revelou a existência de cinco fatores que, atendendo ao princípio de equilíbrio das regras de construção dos itens, responderam por $62,7 \%$ da variância total dos itens. Conclusão: $O$ instrumento possui índice de clareza satisfatório e de validade adequado, todos de acordo com os procedimentos de construção e validação de instrumento de pesquisa. Esse instrumento é cientificamente apropriado para avaliar o conhecimento sobre sua própria doença em pacientes com câncer.

Palavras-chave: Câncer; Questionário; Conhecimento; Paciente. 